\title{
Inter Parental Conflict and Its Effect on Adolescent s Behavior in Selected Schools at Minia City
}

\author{
Elham Rabia Aly Sayied ${ }^{1}$, Yosria El-sayied Hussein ${ }^{2}$, El-Nabgha Fathy Mohammed ${ }^{3}$, Naglaa Mohammed Amein ${ }^{4}$
}

1. B. Sc in Nursing, Minia University, Egypt.

2. Professor of Community Health Nursing, Faculty of Nursing, Minia University, Egypt.

3. Assistant Professor of Department of Psychology, Faculty of Arts, Minia University, Egypt.

4. Lecturer in Community Health Nursing, Faculty of Nursing, Minia University, Egypt.

\begin{abstract}
Background: Inter- parental conflict is emphasized in early and middle childhood, continues to play an important role in adolescence behavior Aim of the study: to assess Inter- Parental Conflict and Its Effect on Adolescents Behavior in selected Schools at Minia City. Research design: A cross-sectional descriptive research design. Sample: Randomly sample by using cluster sample from adolescents $(\mathrm{N}=500)$ in Selected Schools at Minia City. Tools of data collection: first tool Personal and Socio- demographic data, second tool Children's Perception of Inter parental Conflict (CPIC) Scale and third tool Youth Self-Report (YSR) Scale. Results: the majority of the adolescents (95.8\%) reported high perception of inter parental conflict, with perceived threat. Also, normal youth self-report, with more internalizing than externalizing behaviors. The Childrens Perception of Inter parental Conflict and Youth Self-Report scores were significant positively moderate correlated reflecting a negative impact of parental conflict Perception on normal behavior. As well Perception of Inter parental Conflict is lower among urban adolescents (boys), The Youth Self-Report tend to be more normal among rural adolescents (girls). Conclusion: Inter-parental conflict has a detrimental effect on the psychological state and well-being of adolescents. Recommendation: Improve community awareness through modern mass media and communication about the effects of Inter-parental conflict on adolescents.

Keywords: Inter- parental conflict, Adolescence, Schools.
\end{abstract}

\section{Introduction}

Adolescence is a critical time of development in which adolescence are continuously changing mentally, physically and psychologically. They are learning more about the world and trying to strive for parental independence and inclusion in social groups. They want to be perceived as adults with capable decision-making skills (cunsolo, 2017). Interparental conflict (IPC) is a common trait of family life (Baviskar, 2010). Although the role of inter- parental conflict is emphasized in early and middle childhood, conflict between parents continues to play an important role in adolescence (Cummings et al., 2012).

Marital conflict includes marital problems such as a lack of communication, quarrels about children , disagreements over money, and sexual problems. Marital conflict has been linked to internalizing and externalizing problem behavior in children and adolescents. (Roger et al., 2018). Egypt is the most populous country in the Arabic region with 82.5 million inhabitants of which $25 \%$ are adolescents (UNICEF, 2011). Traditionally, adolescents in Egypt live with their parents and some may regularly witness inter-parental conflict. Conflict is defined as any disagreement, difference and argument about an issue that rises in family life (Elemary et al., 2016). Worldwide, around 133 to 275 million children and adolescents witness violence in the home annually (Pinheiro, 2016).

In Egypt there are no statistics on the rate of interparental conflict but one info-graphic study conducted by AlJazeera found that $47 \%$ of married, divorced, widowed women experienced domestic violence (Chughtai A \& O'Toole M, 2016). On the other hand, the nature and quality of school environment perform an important part in forming children's behavior. Rising evidence indicates that schools that present regular, non-punitive and supportive environments decrease hazards of behavior problems (Fergusson et al., 2012). Furthermore, adolescents are aware of the implications of the inter-parental conflict so they are at risk for promoting internalizing and externalizing behaviors (Fisher, 2013).

$P$ a g e $\mid 3$
The community health nurse can be helpful to the adolescents for exploring their feelings about conflict and conflict resolution, listening to adolescents and their families, encouraging them to explore issues and options, and enabling them to manage their personal situations (Kham mash, 2011).

School nursing as Changes in the health care system is shifting the roles specialized practice of professional nursing that advances the well- being, academic success, and life- long achievement of students. Depending on the needs of the school, school district, and community, the role of community health nurses serving in schools (EL-sayed, 2011).

\section{Significance of the study}

Conflict and differences of opinion are inevitable and thus un avoidable experiences for anyone in close personal relationships. Behavioral and emotional problems in adolescents affect a considerable number of young people, with major personal and societal costs. Furthermore, behavior formed in adolescence has implications for individual and public health. For few studies that had been made in this field, this study will be lead to assess and emphasize on adolescents " Perception of inter parental and the effect of this conflict on their behavior (Saber, 2013).

Adolescents are one sixth of the world's populations, a total of 1.2 billion people, and $85 \%$ of them are in the developing world (WHO, 2016). Also, they form around $37.6 \%$ percent of the country's population in Egypt, and represent even greater proportion of the country's human potential (UNICEF, 2016). Before the age of 18 years more than $20 \%$ of the children have experienced parental divorce. It is also estimated that at least 10 million children are exposed to domestic violence annually. Such as, 275 million children worldwide are estimated to witness domestic violence annually. This has a negative impact on children's development Short and long term. Also, 25\% of children are subjected to Physical violence, $36 \%$ for emotional violence .While both divorce and domestic violence represent a great 
result and form of inter-parental conflict (Esfandyari et al., 2015).

\section{Aim of the Study: \\ Assess Inter-Parental Conflict and Its Effect on Adolescent's Behavior in selected Schools at Minia City.}

\section{Research Questions:}

1. How do adolescents perceive and realize inter parental conflict?

2. What the effects are of inter parental conflict on the behavior of adolescents?

\section{Subjects and Method \\ Study design:-}

A cross sectional descriptive research design was used for the current study; this design relevant to the nature of the problem under investigation.

\section{Setting:}

The study was conducted at Three Preparatory Schools (Damaris Preparatory School, Tala Preparatory School for Boys and Tala Preparatory School for Girls) and Three General Secondary Schools (El Salam Secondary School for Boys, El Salam Secondary School for Girls and El Borgaya Secondary Mixed School) were randomly selected from Minia City schools.

\section{Subjects:}

The subjects of this study consisted of adolescents attending preparatory and secondary schools in Minia city during the time of the study. A convenient sample of adolescents according to inclusion and exclusion criteria for 3 months from October 2018 to December 2018. (Number of sample : 500) Inclusion criteria:

- Age from 11 to 18 years.

- Register for the schools in the study setting.

\section{Data Collection Tools}

Data was collected through:-

$1^{\text {st }}$ tool: Personal and Socio- demographic data:-

It was developed by the investigator and it was a structured interviewing questionnaire which was consisted of the following parts: Personal data: such as student's age, gender, school grade, residence, birth order, siblings, etc. Family data: such as parent's age, occupation, etc. Socioeconomic data: crowding index, family income, home utilities, and media at home. Leisure habits: such as favorite hobbies, number of friends, etc. Social relationships: such as the relationships with parents, peers, and siblings.

\section{$2^{\text {nd }}$ tool: Children's Perception of Inter parental Conflict (CPIC) Scale:-}

This scale was modified by (Saber, 2013) guided by (Grych et al., 1992) to assess marital conflict from the child's perspective .It consists of 51 statements with three possible responses: "True", "Sort of True", or "False." The tool items are categorized under three subscales addressing: (Conflict properties, Perceived Self-Blame and Perceived Threat subscale), with 13 non-scored items.

Scoring System: - The statements have three possible responses: "True", "Sort of True", or "False." Each response is assigned a score between 0 and 2, with higher scores indicating more negative conflict or appraisal. Item scores are summed for each subscale (e.g., higher scores on the resolution scale represent poorer resolution and higher scores on the blame scale reflect greater self-blame). The scoring was done following the instructions provided (Moura et al, 2010).

\section{$3^{\text {rd }}$ tool: Youth Self-Report (YSR) Scale:-}

This scale was modified by (Saber, 2013) guided by (Achenbach, 1991). This measure consists of a 112 statements that might describe the youth during the preceding six months. The scales enable measurement of the perception of children or teenagers (aged 11 to 18) in terms of their behavior and social skills (Achenbach 1991). The responses are on a 3-point scale: not true, sometimes true, and often true. The items are categorized into the following subscales: (Internalization, Externalization, Social problems, Thought problems, Attention problems and other problems subscale).

Scoring System: - The responses are scored zero for not true, one for sometimes true, and two for often true. The scoring is done according to the instruction manual with calculation of raw scores, $T$ scores, and percentiles (Achenbach, 1991). It has cut off points based on subject's gender for determining whether problems were within the normal range or exceeded the clinical threshold.

\section{Content Validity}

The content validity of the data collection tools as Personal and Socio- demographic data, Children's Perception of Inter parental Conflict (CPIC) Scale and Youth Self-Report (YSR) Scale was determined the tools were submitted to five experts in community health nursing to test their validity. The tools were examined for content coverage, sequence of items, clarity, relevance, applicability, wording, length, format, and overall appearance. Based on experts' comments and recommendations; minor modifications had been made such as rephrasing and rearrangements of some sentences.

\section{Reliability}

The internal consistency of the questionnaires was calculated using Cronbach's alpha coefficients. Test-retest was used. The Cronbach's alpha of the questionnaires were 0.810 , 0.951 and 0.970 respectively indicating good reliability.

\section{Ethical Consideration}

A written approval obtained from the ethics and research committee of the Faculty of Nursing, Mina University. Oral consent obtained from each participant after explaining the nature \& objectives of the study to gain their cooperation. Each assessment sheet was coded and subjects' names were not appearing on the sheets for the purpose of anonymity and confidentiality. Subjects were free to withdraw from the study at any time.

\section{Study Procedure}

Permission to conduct the study was obtained from the Dean of Faculty of Nursing at Minia University. An official letter was obtained from the directors of the selected schools for data collection after approval of ethical committee at Faculty of Nursing, Minia University. This letter was included a brief explanation of the objectives of the study and permission was requested from each director to carry out the study. 
After extensive review of relevant national and international literature, tools of data collections were developed by the researcher in 2018, prior to data collection, tools for data collection translated from English to Arabic version language and transverse translation again from Arabic to English, Study tools were revised by five experts in the field of nursing at the faculty of nursing; Ain Shams, Helwan and Minia University, to test its content validity and feasibility, the necessary modifications were done as rephrasing and rearrangements of some sentences. Pilot study of twenty adolescents was conducted prior to data collection, those excluded from the study.

The investigator visited the selected schools at Minia city two days per week (Sundays and Mondays) to recruit the study sample from October 2018 to December 2018. The average number interviewed subjects were twenty to thirty students per day and average time taken for each was around 50-60 minutes depending on the response of each person.

The participant adolescents were interviewed after obtaining oral consents from each participant adolescents after explaining the nature \& objectives of the study to gain their cooperation. The questionnaire was introduced for the participant adolescents to be filled except in case of the participant being unable to read or write the researcher filled it. The researcher read the questions to the participant and marked exactly their answers. Time taken to fill in study tools ranged from 50 to 60 minutes. Participants were allowed to ask questions and get explanatory answers. Data collection lasts for 3 months from beginning of October 2018 to end of December 2018, then data were coded, tabulated and analyzed by computer using "the statistical package for social science"'(SPSS)version20.

\section{Statistical analysis}

Data were collected, tabulated, and analyzed by computer using "the statistical package for social science" (SPSS) version 20 .Descriptive data were expressed as numbers and percentages. Quantitative data were presented by mean and standard deviation. Correlation was calculated between perception of inter parental conflict scale and youth self-report scale constructs regarding adolescent behaviors using Pearson correlation test. Probability ( $p$-value) equal to or less than 0.05 was considered significant in tests of relationships.

\section{Results}

Table (1). Distribution of the studied adolescent according to their personal characteristic $(\mathbf{N}=500)$

\begin{tabular}{|c|c|c|c|c|}
\hline Data & $\begin{array}{l}\text { Total } \\
\text { n-500 } \\
\end{array}$ & $\begin{array}{l}\text { Rural } \\
\text { n-256 }\end{array}$ & $\begin{array}{c}\text { Urban } \\
\text { n-244 }\end{array}$ & p- value \\
\hline $\begin{array}{l}\text { Age } \\
\text { Range } \\
\text { Mean } \pm \text { SD }\end{array}$ & $\begin{array}{l}12-19 \\
15.1 \pm 1.7\end{array}$ & $\begin{array}{l}12-18 \\
14.1 \pm 1.4\end{array}$ & $\begin{array}{l}12-19 \\
16.1 \pm 1.4\end{array}$ & $0.001^{*}$ \\
\hline $\begin{array}{l}\text { Gender } \\
\text { Male } \\
\text { Female }\end{array}$ & $\begin{array}{l}253(50.6 \%) \\
247(49.4 \%)\end{array}$ & $\begin{array}{l}130(50.8 \%) \\
126(49.2 \%)\end{array}$ & $\begin{array}{l}123(50.4 \%) \\
121(49.6 \%)\end{array}$ & 0.9 \\
\hline $\begin{array}{l}\text { School stage } \\
\text { Preparatory } \\
\text { Secondary }\end{array}$ & $\begin{array}{l}262(52.4 \%) \\
238(47.6 \%)\end{array}$ & $\begin{array}{l}215(84 \%) \\
51(16 \%)\end{array}$ & $\begin{array}{l}47(19.3 \%) \\
197(80.7 \%)\end{array}$ & $0.001 *$ \\
\hline $\begin{array}{l}\text { Number of brother and sisters } \\
<3 \\
\geq 3\end{array}$ & $\begin{array}{l}49(9.8 \%) \\
451(90.2 \%)\end{array}$ & $\begin{array}{l}16(6.2 \%) \\
240(93.8 \%)\end{array}$ & $\begin{array}{l}33(13.5 \%) \\
211(86.5 \%)\end{array}$ & $0.006^{*}$ \\
\hline $\begin{array}{l}\text { Birth order } \\
\text { No } \\
1^{\text {st }} \\
\end{array}$ & $\begin{array}{l}21(4.2 \%) \\
479(95.8 \%)\end{array}$ & $\begin{array}{l}1(9.3 \%) \\
247(96.5 \%)\end{array}$ & $\begin{array}{l}12(4.9 \%) \\
232(95.1 \%)\end{array}$ & 0.4 \\
\hline $\begin{array}{l}\text { Homing with } \\
\text { Both parents } \\
\text { One parents }\end{array}$ & $\begin{array}{l}439(87.8 \% \\
61(12.2 \%)\end{array}$ & $\begin{array}{l}223(87.1 \%) \\
33(12.9 \%)\end{array}$ & $\begin{array}{l}216(88.5 \%) \\
28(11.5 \%)\end{array}$ & 0.6 \\
\hline $\begin{array}{l}\text { If with one parent why } \\
\text { Traveling } \\
\text { Divorce } \\
\text { Death }\end{array}$ & $\begin{array}{l}61 \\
33(54.1 \%) \\
14(23 \%) \\
14(23 \%) \\
\end{array}$ & $\begin{array}{l}33 \\
18(54.5 \%) \\
7(21.2 \%) \\
8(24.2 \%) \\
\end{array}$ & $\begin{array}{l}28 \\
15(53.6 \%) \\
7(25 \%) \\
6(21.4 \%)\end{array}$ & 0.9 \\
\hline
\end{tabular}

\section{$\mathrm{p} \leq 0.05$ (significant)}

Table 1: shows that age of the studied adolescent ranged from 12-19 with mean of $15.1 \pm 1.7$, half of the adolescents there was $50.9 \%$ male, $52.4 \%$ preparatory school, and the majority of the adolescents $95.8 \%$ was the first child. $87.8 \%$ live with both parents, $90.2 \%$ had more than 3 brothers. There was significant difference between rural and urban regarding age, school stage, and number of brothers.

Table (2). Distribution of the studied adolescent according to their conflict properties subscale. ( $N=500)$

\begin{tabular}{|l|l|l|l|l|l|}
\hline \multicolumn{2}{|c|}{ conflict properties } & \multicolumn{1}{|c|}{$\begin{array}{c}\text { Total } \\
\text { n-500 }\end{array}$} & \multicolumn{1}{|c|}{$\begin{array}{c}\text { Rural } \\
\text { n-256 }\end{array}$} & \multicolumn{1}{|c|}{$\begin{array}{c}\text { Urban } \\
\text { n-244 }\end{array}$} & \multicolumn{1}{c|}{ p } \\
\hline \multirow{3}{*}{ Frequency } & Low & $181(36.2 \%)$ & $87(34 \%)$ & $94(38.5 \%)$ & 0.2 \\
& High & $319(63.8 \%)$ & $169(66 \%)$ & $150(61.5 \%)$ & \\
\cline { 2 - 6 } & Mean \pm SD & $11.1 \pm 2.6$ & $11.5 \pm 2.5$ & $10.7 \pm 2.6$ & $0.001^{*}$ \\
\hline \multirow{3}{*}{ Intensity } & Low & $175(35 \%)$ & $81(31.6 \%)$ & $94(38.5 \%)$ & 0.1 \\
& High & $325(65 \%)$ & $175(68.4 \%)$ & $150(61.5 \%)$ & \\
\cline { 2 - 6 } & Mean \pm SD & $13.5 \pm 3.2$ & $14.2 \pm 3.2$ & $12.8 \pm 3.1$ & $0.001^{*}$ \\
\hline \multirow{3}{*}{ Resolution } & Low & $154(30.8 \%)$ & $62(24.2 \%)$ & $92(37.3 \%)$ & $0.001^{*}$ \\
& High & $346(69.2 \%)$ & $194(75.8 \%)$ & $152(62.3 \%)$ & \\
\cline { 2 - 6 } & Mean \pm SD & $11.1 \pm 2.3$ & $11.4 \pm 2.1$ & $10.7 \pm 2.5$ & $0.001^{*}$ \\
\hline \multirow{2}{*}{ Total } & Low & $201(40.2 \%)$ & $89(34.8 \%)$ & $112(45.9 \%)$ & $0.01^{*}$ \\
& High & $299(59.8 \%)$ & $167(65.2 \%)$ & $132(54.1 \%)$ & \\
\hline
\end{tabular}


N.B -significant is considered at ( $\mathrm{p}$-value $<0.05)$.

\begin{tabular}{|c|c|c|c|c|}
\hline conflict properties & $\begin{array}{l}\text { Total } \\
\text { n-500 }\end{array}$ & $\begin{array}{l}\text { Rural } \\
\text { n-256 }\end{array}$ & $\begin{array}{l}\text { Urban } \\
\text { n-244 }\end{array}$ & $\mathbf{p}$ \\
\hline Mean \pm SD & $35.8 \pm 7.1$ & $37.3 \pm 6.3$ & $34.2 \pm 7.5$ & $0.001 *$ \\
\hline
\end{tabular}

-Significant is considered highly significant at $(\mathrm{p}$-value $<0.01)$

Table (2): showing that distribution of the studied adolescent according to their conflict properties subscale , about two third $63.8 \%$ had high frequency of conflict, $65 \%$ higher intensity, $69.2 \%$ had high score of resolution with significant higher scores in rural than urban.

Table (3): Distribution of the studied adolescent according to their externalizing sub scale. $\mathbf{N}=500$

\begin{tabular}{|l|l|l|l|c|}
\hline \multicolumn{2}{|c|}{ Data } & \multicolumn{1}{|c|}{$\begin{array}{c}\text { Male } \\
\text { n-253 }\end{array}$} & \multicolumn{1}{|c|}{$\begin{array}{c}\text { Female } \\
\text { n-247 }\end{array}$} & \multicolumn{1}{c|}{ P } \\
\hline Delinquent behavior & Normal & $223(88.1 \%)$ & $203(82.2 \%)$ & $0.001^{*}$ \\
& Border line & $4(1.6 \%)$ & $22(8.9 \%)$ & \\
& Clinical & $26(10.3 \%)$ & $22(8.9 \%)$ & \\
\hline Aggressive behavior & Normal & $223(88.5 \%)$ & $208(84.2 \%)$ & 0.3 \\
& Border line & $3(1.2 \%)$ & $4(1.6 \%)$ & \\
& Clinical & $26(10.3 \%)$ & $35(14.2 \%)$ & \\
\hline
\end{tabular}

Distribution of the studied adolescent according to their externalizing sub scale. $\mathrm{N}=500$

Table (3): showing that distribution of the studied adolescent according to their externalizing subscale, $10.3 \%$ had clinical delinquent, $14.2 \%$ had clinical aggressive behavior. These syndromes higher significant among male than female.

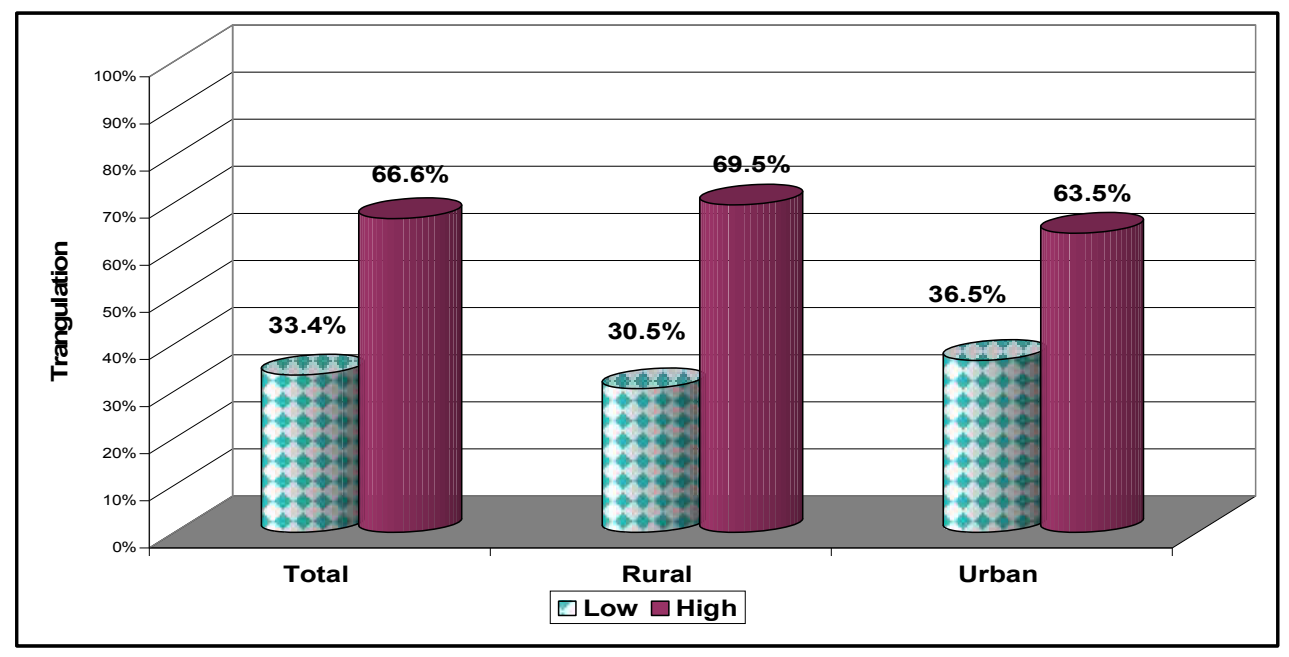

Figure (1): Distribution of the studied adolescent according to their triangulation. $\mathbf{N}=\mathbf{5 0 0}$

Figure (1): showing that distribution of the studied adolescent according to their triangulation, $66.6 \%$ had high triangulation score, significant high mean score among rural than urban.

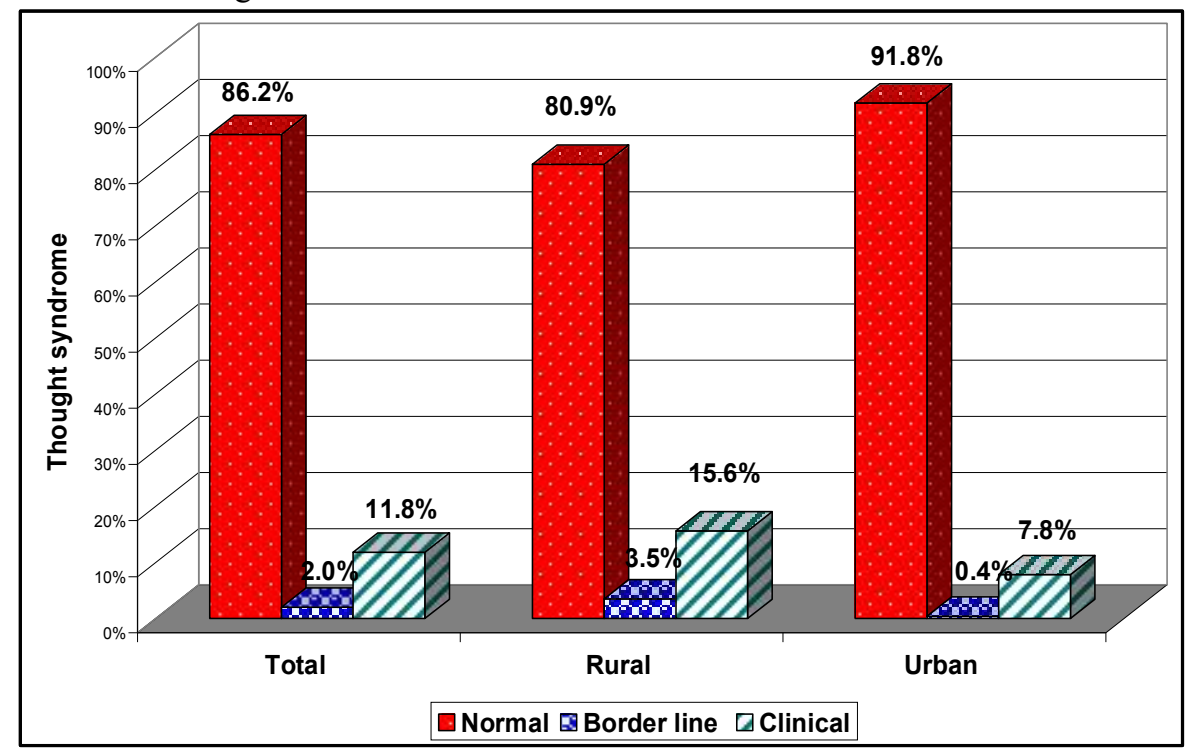

Figure (2): Distribution of the studied adolescent according to thought problem sub scale. $\mathbf{N}=\mathbf{5 0 0}$

Figure (2): showing that distribution of the studied adolescent according to thought problem sub scale, $11.8 \%$ had clinical thought problem. This problem was clinically higher among rural than urban. 
Minia Scientific Nursing Journal (Print) (ISSN 2537-012X) Vol. (6) No. (1) December 2019

Table (4): Correlation of conflict properties subscale with youth self-report scale among the studied adolescent: $(\mathrm{N}=500)$

\begin{tabular}{|c|c|c|c|c|c|}
\hline \multirow{2}{*}{\multicolumn{2}{|c|}{ Youth self-report scale }} & \multicolumn{4}{|c|}{ conflict properties } \\
\hline & & \multirow{2}{*}{$\begin{array}{c}\text { Frequency } \\
0.50 \\
0.0001 *\end{array}$} & \multirow{2}{*}{$\begin{array}{c}\text { Intensity } \\
0.58 \\
0.0001 *\end{array}$} & \multirow{2}{*}{$\begin{array}{c}\text { Resolution } \\
0.51 \\
0.0001 *\end{array}$} & \multirow{2}{*}{$\begin{array}{c}\text { Total } \\
0.63 \\
0.001^{*}\end{array}$} \\
\hline Anxious/depressed & $\begin{array}{l}\mathbf{r} \\
\mathbf{p}\end{array}$ & & & & \\
\hline Withdrawal & $\begin{array}{l}\mathbf{r} \\
\mathbf{p}\end{array}$ & $\begin{array}{c}0.54 \\
0.0001 * \\
\end{array}$ & $\begin{array}{c}0.59 \\
0.0001^{*}\end{array}$ & $\begin{array}{c}0.50 \\
0.0001^{*}\end{array}$ & $\begin{array}{c}066 \\
0.001 *\end{array}$ \\
\hline Somatic syndrome & $\begin{array}{l}\mathbf{r} \\
\mathbf{p}\end{array}$ & $\begin{array}{c}0.51 \\
0.0001 *\end{array}$ & $\begin{array}{c}0.63 \\
0.0001 * \\
\end{array}$ & $\begin{array}{c}0.50 \\
0.001 *\end{array}$ & $\begin{array}{c}0.63 \\
0.001^{*} \\
\end{array}$ \\
\hline Delinquent behavior & $\begin{array}{l}\mathbf{r} \\
\mathbf{p}\end{array}$ & $\begin{array}{c}0.51 \\
0.0001 *\end{array}$ & $\begin{array}{c}0.63 \\
0.0001 *\end{array}$ & $\begin{array}{c}0.47 \\
0.0001 *\end{array}$ & $\begin{array}{c}0.63 \\
0.001 *\end{array}$ \\
\hline Aggressive behavior & $\mathbf{r}$ & $\begin{array}{c}0.55 \\
0.0001 *\end{array}$ & $\begin{array}{c}0.63 \\
0.0001 *\end{array}$ & $\begin{array}{c}0.52 \\
0.0001 *\end{array}$ & $\begin{array}{c}0.64 \\
0.001^{*} \\
\end{array}$ \\
\hline Social syndrome & $\mathbf{r}$ & $\begin{array}{c}0.56 \\
0.0001^{*}\end{array}$ & $\begin{array}{c}0.62 \\
0.0001 *\end{array}$ & $\begin{array}{c}0.55 \\
0.0001^{*}\end{array}$ & $\begin{array}{c}0.67 \\
0.001 *\end{array}$ \\
\hline Thought syndrome & $\begin{array}{l}\mathbf{r} \\
\mathbf{p}\end{array}$ & $\begin{array}{c}0.52 \\
0.0001 *\end{array}$ & $\begin{array}{c}0.58 \\
0.0001 *\end{array}$ & $\begin{array}{c}0.52 \\
0.0001 *\end{array}$ & $\begin{array}{c}0.62 \\
0.001 *\end{array}$ \\
\hline Attention syndrome & $\begin{array}{l}\mathbf{r} \\
\mathbf{p}\end{array}$ & $\begin{array}{c}0.58 \\
0.0001 *\end{array}$ & $\begin{array}{c}0.61 \\
0.0001 *\end{array}$ & $\begin{array}{c}0.54 \\
0.0001 *\end{array}$ & $\begin{array}{c}0.67 \\
0.001 *\end{array}$ \\
\hline Others & $\begin{array}{l}\mathbf{r} \\
\mathbf{p}\end{array}$ & $\begin{array}{c}0.52 \\
0.0001 \\
\end{array}$ & $\begin{array}{c}0.57 \\
0.0001 *\end{array}$ & $\begin{array}{c}0.42 \\
0.0001 *\end{array}$ & $\begin{array}{c}0.58 \\
0.001 *\end{array}$ \\
\hline Total & $\mathbf{r}$ & $\begin{array}{c}0.70 \\
0.0001^{*}\end{array}$ & $\begin{array}{c}0.80 \\
0.0001^{*}\end{array}$ & $\begin{array}{c}0.63 \\
0.0001^{*} \\
\end{array}$ & $\begin{array}{c}0.82 \\
0.001 * \\
\end{array}$ \\
\hline
\end{tabular}

$\mathrm{p} \leq 0.05$ (significant)

$\mathrm{P}$ - Value based on compares means

Table (4): Showing that there was significant positive moderate correlation between youth self- report sub scales and conflict frequency, intensity and resolution.

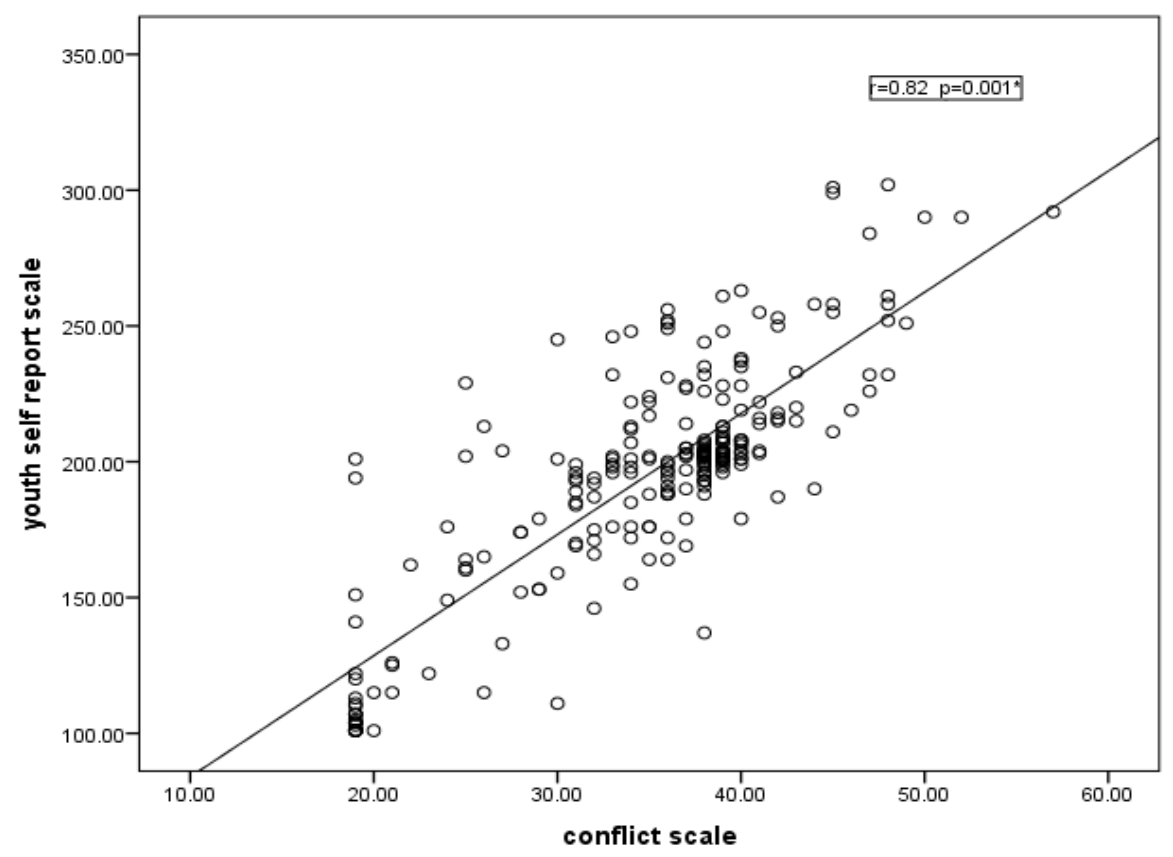

Figure (3): Correlation of conflict properties subscale with youth self-report scale among the studied adolescent. $\mathrm{N}=500$

Figure (3) scattered diagram: illustrated that there was positive correlation between youth self- report sub scales and conflict frequency, intensity and resolution scores $(\mathrm{r}=0.82)$ with moderate statistically significant correlation $(\mathrm{p}=0.001)$.

\section{Discussion}

When adolescents witnessed inter-parental conflict they complained of negative psychosocial consequences, which expose them to sense of insecurity that may place them at risk of internalizing and externalizing their adjustment difficulties Elemary et al., (2016). Therefore, this study aimed to assess Inter Parental Conflict and Its Effect on Adolescent's Behavior. As well, this result showed that more than half of the adolescents resided in rural areas. This might be due to the high cost of living requirements and low socioeconomic level in rural areas, so they have an economic view of the family conflict because has negative effects on adolescent behavior. These results were in $P$ a g e $\mid 7$ accordance with the study of Abdul Kadir et al., (2018) that describes a study of at-risk youth using self-report ratings in communities of the urban poor who were identified as demonstrating a pervasive conflict with their parents. Both mother and father conflicts are significantly related to negative affect.

Larsson, T. (2014) demonstrated that a higher degree of emotional problems in girls than boys. Also, showed that girls and boys have similar rates of use and abuse in adolescence; however their respective risk factors have usually been reported as internalizing disorders for girls and externalizing disorders for boys. Consistent with earlier findings, adolescent girls in the current study were more likely

Elham R., et al 
than adolescent boys to develop internalizing problems but adolescent boys were more likely than adolescent girls to develop externalizing problems.

Triangulation means siding with one parent in the argument and this is a significant aspect of childrens perception of inter-parental conflict. The present study results showed that two thirds of the studied adolescents felt triangulation during the parent conflict. On the contrary, Saber, N. (2013) mentioned that triangulation was low among adolescents because it may make the adolescent feel insecure about the future stability of the family unit. Meanwhile, Fisher, (2013) mentioned that parents may be unaware of triangulation within the family or unaware of the potential negative effect on the adolescent. Therefore, the present study demonstrated that the feeling of threat was highest; self-blame was highest, while the Coping efficiency was midway. Low threats higher among rural than urban, and high coping was higher among rural than urban.

On the contrary, Saber, N. (2013) stated that the threat sensation was highest; self-blame was lowest, while the Coping efficacy was halfway. According to the results of the current study, it is clear that the majority of adolescents had a good relationship with their parents, siblings and friends. These close relationships are considered support in case of conflict. In congruence with this, Van Lissa et al., (2015) stated that only low-empathy adolescents experienced elevated conflict, whereas only high-empathy adolescents were in agreement with parents about the frequency of conflict throughout adolescence.

Furthermore, the results of the present study showed the association between the high percentages of normal behavior of adolescents and the self-report of youth (YSR) regarding internalizing behavior as depression, anxiety, and somatic complaints, and the externalizing behavior as delinquent behavior and aggressive behavior. On the same way, Chen, (2017) observed that parents in high socio economic status families tended to report lower scores for adolescent emotional and behavioral problem syndromes. Also, the results of the current study showed that the problems of internalizing behavior were higher in male adolescents than females. On the contrary, Larsson, T. (2014) show that females are more likely to have an affective disorder such as depression whereas males are more likely to have an externalizing disorder such as conduct disorder. In addition, Khalil et al. (2010) in a study conducted in Egypt found that girls reported anxiety and depression more than boys.

The results of the present study showed significant positive moderate correlation between youth self- report subscales and conflict frequency, intensity and resolution indicating that the highest perception of children in the family conflict (CPIC) score is related with the highest youth selfreport (YSR) score. As well this showed that more perception is associated with more behavior problems. Also, this result is in line with the study of Ross and Fuertes (2010) which shows that perceptions of inter parental conflict would be inversely related to attachment security when utilizing model. Our findings showed that children's perception of their ability to cope is important in understanding the effect of parental conflict on children's psychological maladjustment Camisasca et al., (2017). Also, the results of the current study have shown that inter-parental conflict had a significant positive fair correlation with youth incompatibility, both internalizing and externalizing.

\section{Conclusion:}

Based on the findings of the present study, it can be concluded that, there was a high perception of inter parental conflict (CPIC) with threat and self-blame more prominent among girls, with more internalizing behavior than externalizing behavior and also more triangulation among girls. The CPIC and youth self-report (YSR) scores are significant positive moderate correlation reflecting a negative impact of parental conflict perception on normal behavior. Thus, inter parental conflict as measured by self-reporting has negative effects on psychological state of adolescents.

\section{Recommendation:}

- Develop programs for adolescents for conflict resolution strategies and enable them to adapt more to the marital debate of parents.

- Periodical workshops for school students to develop programs to cover good relationships and how to give solutions to the conflict and how to develop good means to express their emotions.

- Further research to study the Comparison between constructive marital conflict effects versus destructive marital conflict effects between adolescents.

- Further research to study developing school curricula to include behavioral and emotional problems for children and adolescents.

\section{Reference}

1) Abdul Kadir, N. B, Hoesni, S. M and Zakaria, S, $M$ (2018). The Correlates of Conflict and Behavioral Difficulties on the Negative Affect in At Risk Youth in Malaysia, Journal Psychology Malaysia 32 (1) University Kebangsaan Malaysia.

2) Achenbach, T. M. (1991). Manual for the youth selfreports. Burlington, Vermont: University of Vermont: Department of Psychiatry.

3) Baviskar, S. (2010). Does child gender moderate the relationship between Inter parental conflict and child outcomes? Findings from the Danish Longitudinal Study of Children. Norsk Epidemiology.; 20(1), 63.

4) Camisasca, E., Miragoli, S., Di Blasio, P. et al. (2017). J Child Fam Stud 26: 1099. https:///doi.org/10.1007/s10826-016-0645-9.

5) Chen Y-Y, Ho S-Y, Lee P-C, Wu C-K and Gau SS-F (2017). Parent-child discrepancies in the report of adolescent emotional and behavioral problems in Taiwan. PLoS ONE 12(6): e0178863. https:///doi.org/10.1371/journal.pone.0178863.

6) Chughtai A. and O'Toole M. (2016). Infographic: Violence against women in Egypt. Qatar: Aljazeera; $2015 \quad$ [cited $2016 \quad 8 . \quad$ January]. Availablefrom:https:///www.aljazeera.com/indepth/in teractive/2015/01/info-graphic-violence-womenegypt-150126150958383.html.

7) Cummings, E. M., George, M. R., McCoy, K. P., and Davies, P. T. (2012). Inter-parental conflict in kindergarten and adolescent adjustment: Prospective investigation of emotional security as an explanatory mechanism. Child Development, 83(5), 1703-1715. doi:10.1111/j.1467-8624.2012.01807.x.

8) Cunsolo, S. (2017). Subjective wellbeing during adolescence: a literature review on key factors relating to adolescent's Subjective wellbeing and 
education outcomes, University di Firenze, P.81. Available at: www.fupress.net/index.php/sf/article/veiwfile/2094/1 9448.

9) Elemary, F. M., Omari, O. A., and Wynaden, D. (2016).Psychiatric-Mental Health Nursing, Ain Shams University, Cairo, Egypt January 14, 2016, Journal of Nursing Education and Practice, DOI: $10.5430 /$ jnep.v6n5p84,URL: http://dx.doi.org/10.5430/jnep.v6n5p84.

10) EL-sayed, M. A. (2011). Assessment of Health Practices among adolescent students in Schools, faculty of Nursing, Cairo University, Egypt.

11) Esfandyari B, Baharudin $R$ and Nowzari $L$. (2015). The relationship between inter-parental conflicts and externalizing behavior problems among adolescents.

https://www.who.int/topics/violence/interpersonalviolence-against-women-children/in/2015. https://www.unicef.org/violencestudy/arabic/2004./2 $\% 20$ StudyFindingsPressKitAr.pdf.

12) Fergusson, D., Boden, J., and Hayne, H. (2012). Improving the Transition: Reducing Social and Psychological Morbidity during Adolescence. Office of the Prime Minister's Science Advisory Committee. New Zeeland. (Jan 22,); Chapter 4.Pp.61-62. https://www.pmcsa.org.nz/wp-

content/uploads/Improving-the-Transition-report.pdf.

13) Fisher, S.D., (2013). "Mediators of interparental conflict and adolescent internalizing/externalizing behaviors." PhD (Doctor of Philosophy) thesis, University of Iowa. http://ir.uiowa.edu/etd/3293.

14) Grych, J. H., Seid, M., and Finch am, F.D. (1992). Assessing marital conflict from the child's perspective: The Children Perception of Interparental Scale. Child Development; 63,558-572.

15) Khalil, A.H., Rabie, M.A., Abd-El-Aziz,M.F., Abdou, T.A., El-Rasheed , A.H., and Sabry, W.M. (2010). Clinical characteristics of depression among adolescent females: a cross-sectional study. BioMed Central Ltd. Retrieved (Jan 4, 2013) from http:///www.capmh.com/content/4/1/26

16) Kham mash, A.M.S. (2011). Assessment of health risk behaviors among university students in Jordan. Faculty of Nursing Alexandria University: Unpublished Doctorate Thesis.P3.
17) Larsson, T. (2014). Associations between Depression, Problem Behavior and Severity of Substance Abuse, Psychology C, Örebro University.

18) Moura,O.,Santos,R.A.,Rocha,M., and Matos,P.M.(2010).Children's Perception Of Inter parental Conflict Scale(CPIC):Factor Structure and Invariance Across Adolescents and Emerging Adults. International Journal of Testing, 10, 364-382.

19) Pinheiro, P.(2016). World report on violence against children Geneva, Switzerland: United Nations Secretary-General's Study on Violence Against Children; 2006 [cited 2016 08, January]. Available from: http://www.unicef.org /violencestudy/reports.html.

20) Roger J. R. Levesque, 28 February (2018). Marital harmony and adolescent adjustment. DOI: https://doi/org/10.1007/978-3-319-33228-4_453

21) Ross, J. and Fuertes, J. (2010). Parental Attachment, Inter-parental Conflict and Young Adults Emotional Adjustment. Fordham University, New York, NY, USA.http:///www:sagepub.com/journalsPermissions. Nav.DOI: $\quad 10.1177 / 0011000010376094$. http://tcp.sagepub.com

22) Saber, N. EL. A. (2013). Effect of Inter Parental Conflict on Adolescents' Behavior in Zagazig City. Manual for the youth self-reports, assessing marital conflict from the child's perspective. At Faculty of Nursing Zagazig University.

23) United Nations International Children's Emergency Fund [UNICEF]. Adolescence. (2011). Available from: http://www.unicef.org/e gypt/children_151.html.

24) United Nations International Children's Emergency Fund (UNICEF) Adolescence. (Jan 10, 2016).

http://www.unicef.org/egypt/children 151.html. https:///www.ahram.org.eg/NewsQ/557816.aspx,201 6.

25) Van Lissa, C.J., Hawk, S.T., Branje, S.J.T. et al. (2015). J Youth Adolescence 44:48.https:///doi.org/10.1007/s10964-014-0152-5.

26) World Health Organization (WHO) (2016). Helping parents in developing countries improve adolescents' health. (Online). (Sep 13), https://hrweb.mit.edu/worklife/raisingteens/pdfs/helping-parents.pdf 